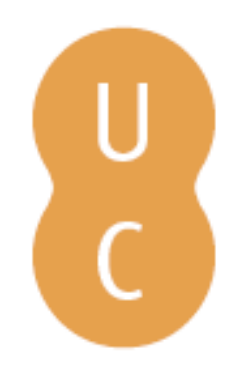

\title{
nombalina
}

\section{Benchmarking dos serviços dos hospitais portugueses: uma aplicação de data envelopment analysis}
Autor(es):
Castro, Ricardo A. S.; Portela, Conceição Silva; Camanho, Ana S.
Publicado por: Imprensa da Universidade de Coimbra
URL
persistente:
URI:http://hdl.handle.net/10316.2/35942
DOI:
DOI:http://dx.doi.org/10.14195/978-989-26-0738-2_20
Accessed : $\quad$ 26-Apr-2023 14:56:35

A navegação consulta e descarregamento dos títulos inseridos nas Bibliotecas Digitais UC Digitalis, UC Pombalina e UC Impactum, pressupõem a aceitação plena e sem reservas dos Termos e Condições de Uso destas Bibliotecas Digitais, disponíveis em https://digitalis.uc.pt/pt-pt/termos.

Conforme exposto nos referidos Termos e Condições de Uso, o descarregamento de títulos de acesso restrito requer uma licença válida de autorização devendo o utilizador aceder ao(s) documento(s) a partir de um endereço de IP da instituição detentora da supramencionada licença.

Ao utilizador é apenas permitido o descarregamento para uso pessoal, pelo que o emprego do(s) título(s) descarregado(s) para outro fim, designadamente comercial, carece de autorização do respetivo autor ou editor da obra.

Na medida em que todas as obras da UC Digitalis se encontram protegidas pelo Código do Direito de Autor e Direitos Conexos e demais legislação aplicável, toda a cópia, parcial ou total, deste documento, nos casos em que é legalmente admitida, deverá conter ou fazer-se acompanhar por este aviso.

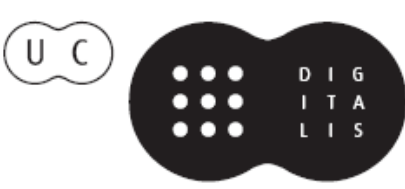




\section{INVESTIGAÇÃO OPERACIONAL EM AÇÃO \\ CASOS DE APLICAÇÃO}

RUI CARVALHO OLIVEIRA JOSÉ SOEIRO FERREIRA (EDITORES)

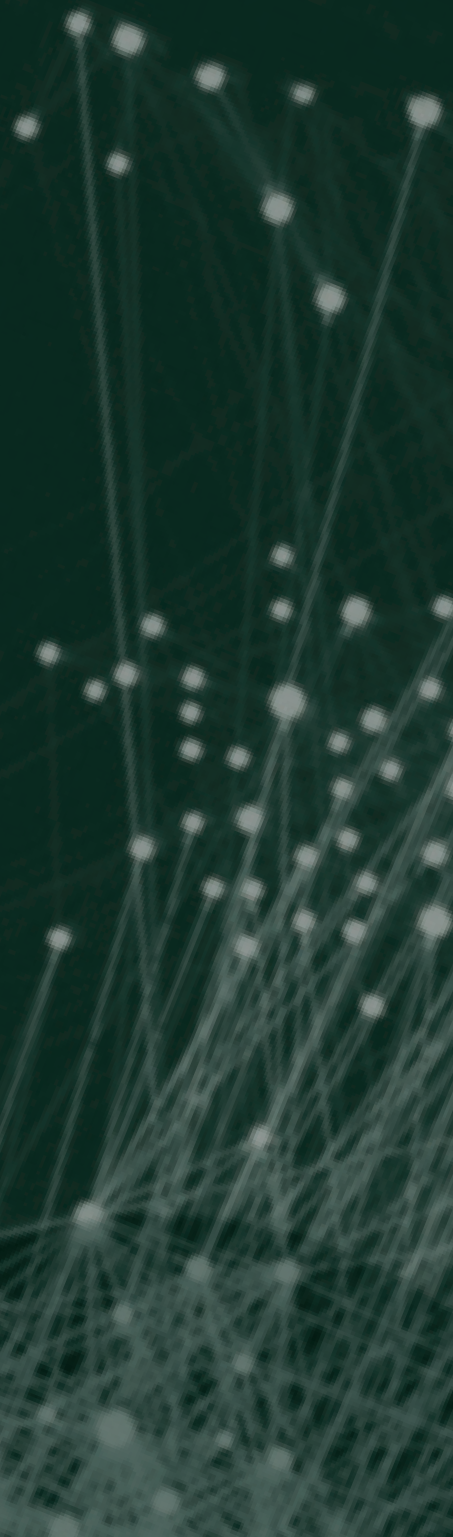




\section{CASO 20}

\section{BENCHMARKING DOS SERVIÇOS DOS}

Hospitais Portugueses:

UMA APLICAÇÃo DE DATA ENVELOPMENT ANALYSIS

Ricardo A. S. Castro Faculdade de Engenharia da Universidade do Porto ricardo.alves.castro@fe.up.pt

Conceição Silva Portela Universidade Católica Portuguesa no Porto csilva@porto.ucp.pt

Ana S. Camanho Faculdade de Engenharia da Universidade do Porto acamanho@fe.up.pt 


\section{RESUMO}

Neste artigo, apresentamos a aplicação de um modelo de Data Envelopment Analysis aos serviços de Medicina Interna da maioria dos hospitais do Serviço Nacional de Saúde Português, numa perspetiva de eficiência. O modelo de avaliação é apresentado para a generalidade dos serviços hospitalares, tendo os inputs e outputs sido escolhidos após análise dos seus impactos nos gastos globais dos diferentes serviços. Nesta aplicação impõem-se restrições aos pesos, por forma a evitar obter serviços com pesos pouco razoáveis para as variáveis do modelo. Observa-se que as maiores poupanças são possíveis nos medicamentos e material clínico. É feita uma comparação entre serviços eficientes e ineficientes, observando-se que os meios complementares de diagnóstico e terapêutica (recursos) e as variáveis de acesso aos cuidados (elementos da produção) são determinantes na definição do melhor desempenho dos serviços de Medicina Interna analisados.

\section{PALAVRAS-CHAVE}

Data Envelopment Analysis, Avaliação de hospitais, Benchmarking, Análise de eficiência 


\section{Introdução: Avaliação de Hospitais - Motivação e Desafios}

Este artigo apresenta brevemente o contexto hospitalar nacional e os problemas inerentes à avaliação de unidades tão complexas quanto os hospitais. Pretende-se com este estudo apresentar uma abordagem à avaliação de serviços hospitalares usando Data Envelopment Analysis (DEA), com base em dados cedidos pela Administração Central do Sistema de Saúde (ACSS). A maioria dos dados, relativos a 2008, pode ser consultada na Base de Dados dos Elementos Analíticos (contabilidade de gestão) dos hospitais do Serviço Nacional de Saúde (SNS), disponível no sítio da ACSS. Os restantes dados referem-se aos recursos e à produção dos hospitais, também cedidos pela ACSS.

\subsection{Os Gastos em Saúde na OCDE, UE e Portugal e a Agenda Política para o} Setor

Em todos os países da Organização para a Cooperação e Desenvolvimento Económico (OCDE) tem-se assistido a um aumento constante das despesas em saúde. Existem diversas razões que levam a este aumento, destacando-se, do lado da procura, o envelhecimento da população, o alargamento do acesso e da cobertura dos diferentes seguros/sistemas nacionais de saúde e o crescimento do rendimento das populações. Enquanto as duas primeiras razões parecem óbvias, a terceira tem sido bastante estudada, existindo evidência que o que a sustenta é a correlação existente entre o aumento do rendimento e a maior exigência e consumo de serviços de saúde (Simões, 2004). Do lado da oferta, pode destacar-se o aumento da complexidade tecnológica das ferramentas de diagnóstico e tratamento disponíveis, assim como o aumento da formação do pessoal hospitalar. Em Portugal, desde a criação do SNS, em 1979, o aumento dos gastos com a saúde tem sido superior à média da OCDE e da União Europeia a 15 países (UE-15). Em 2004, estes gastos atingiram o valor de 10\% do Produto Interno Bruto (PIB) (Oliveira et al., 2007), dos quais 7\% eram gastos públicos. Dados do Instituto Nacional de Estatística (INE) revelam que, de 2005 a 2008, o valor total da despesa em Portugal se situou, em média, em

torno dos 9,5\% do PIB (Pordata). Desta despesa, neste último período, a percentagem de despesa pública correspondeu a um valor compreendido entre 
os 65\% e os 70\% (Pordata, 2011), sendo a restante despesa proveniente das famílias, de seguros sociais, entre outras fontes privadas. Em 2004, os valores referidos fizeram Portugal aproximar o nível de despesa pública em saúde com o da OCDE e EU-15 (Oliveira et al., 2007), sem, no entanto, a ultrapassar. Portugal e a grande maioria dos países da OCDE apresentam mecanismos de proteção dos seus cidadãos na doença e, por isso, apresentam uma preponderância dos gastos públicos em saúde, face aos gastos privados. No nosso país, a maior parte da despesa pública incorrida pelo Serviço Nacional de Saúde (SNS) deve-se aos hospitais (mais de 50\%).

Os aumentos de custos com saúde que se têm verificado no mundo ocidental, em especial no espaço europeu, têm exercido uma grande pressão sobre os défices nacionais, o que tem levado os diversos Estados a agir no sentido da sua contenção, tendo em vista a sustentabilidade dos sistemas de saúde no longo prazo. Muito em voga até ao fim da década de 80, a doutrina "mais mercado" na Saúde foi abandonada, mesmo pelo Banco Mundial, tendo o enfoque passado a ser a eficiência da intervenção estatal (Simões, 2004). No final da década de 90 e no princípio deste século, foram tomadas diversas medidas transversais a toda a União Europeia, que tinham como objetivo conter o aumento dos custos com a saúde, através de um aumento da eficiência (Simões, 2004). Em Portugal, a agenda política vigente, que tem conduzido as reformas efetuadas na última década, pode resumir-se numa delegação da responsabilidade de execução para níveis mais próximos do utilizador, numa responsabilização dos prestadores pelo desempenho e mesmo numa flexibilização da gestão dentro do setor público (Simões, 2004). Na prática, a execução desta agenda política tem levado à tentativa de mudança do paradigma hospitalocêntrico, sendo de destacar: a criação de unidades de internamento de longo prazo, inseridas na Rede de Cuidados Continuados (rede que promove a substituição do hospital como centro de tratamento de doentes crónicos), o desenvolvimento de serviços de cuidados paliativos (cuidados prestados no sentido de tratar e cuidar de doentes na fase final da vida), a reorganização do mapa hospitalar público e a transformação de hospitais do setor público administrativo em hospitais entidade pública empresarial, com independência de gestão e financiados pelo Ministério da 
Saúde. Como conclui o relatório de Barros e Simões (2007) para o Observatório Europeu de Sistemas e Políticas de Saúde, o paradigma hospitalocêntrico vigente não se tinha alterado até à data (e não se alterou até ao ano de 2012), continuando-se as reformas para o alterar.

\subsection{A Necessidade de Avaliação Hospitalar e Seus Problemas}

A necessidade de controlar mais de perto a despesa pública tem levado à gradual aceitação da necessidade de se introduzirem mecanismos de avaliação mais profundos nos processos de tomada de decisão nas administrações públicas, nomeadamente ao nível da saúde. O princípio geral de prestar contas tem ganho espaço, devido ao aumento progressivo da informação, conhecimento e sentido crítico dos cidadãos. Esta avaliação dos serviços da Administração Pública é muitas vezes tida como uma exigência decorrente da responsabilização pela utilização de fundos estatais destinados a responder a necessidades públicas (Simões, 2004).

As políticas nacionais para o setor da saúde, nomeadamente a que conduziu à introdução de hospitais empresa e à separação do papel do Estado como prestador e financiador (Lei 27/2002 de 8 de Novembro), supõem, pela sua natureza, a criação de mecanismos de avaliação por parte das próprias instituições hospitalares e quase forçam uma avaliação aos hospitais, para se aferir o impacto da sua implementação. No entanto, a extensão de estudos de avaliação do desempenho hospitalar, em Portugal, é ainda reduzida. Existem, no entanto, exemplos de programas de certificação e acreditação promovidos principalmente por entidades anglófonas e mesmo alguns programas de benchmarking. É, contudo, de esperar uma evolução significativa neste campo, já que a cada vez maior penetração de software de gestão hospitalar poderá permitir a organização de cada vez maiores quantidades de informação com acesso mais fácil.

Apesar de necessária, a avaliação do desempenho de um hospital não é uma atividade trivial (Costa e Lopes, 2007). Das diferentes dificuldades, podem destacar-se a inexistência de objetivos claros e comuns para a atividade de todas as unidades, a existência de objetivos não mensuráveis (Simões, 2004) ou mesmo a existência de diferentes agentes (Costa e Lopes, 2007) no processo da 
prestação de cuidados de saúde. Neste processo, o médico terá tendência a maximizar o estado de saúde dos indivíduos (maximizando a eficácia da atividade hospitalar), enquanto o gestor do hospital se preocupará mais com a minimização dos recursos usados para a prestação dos cuidados (maximização da eficiência da atividade hospitalar, que pode ser conflituante com a eficácia). No entanto, a única maneira de se praticar gestão e tomar decisões baseadas em factos é medindo esta atividade hospitalar, realizando um processo avaliativo que permita priorizar as oportunidades de melhoria e avaliar o desempenho do que se tem realizado. Para que a avaliação reflita da melhor forma a complexidade inerente ao setor da saúde, os indicadores escolhidos para medir a atividade de um prestador de cuidados deverão ter em conta os aspetos relacionados com a qualidade dos tratamentos, isto é, com o seu impacto na saúde das pessoas que os recebem (Marshall et al., 2004).

Num processo avaliativo, é conveniente não esquecer que a avaliação de um sistema tão complexo como o hospitalar pode trazer consigo algumas consequências indesejadas, fruto da usual utilização de um reduzido número de indicadores de desempenho (usualmente necessária para permitir a exequibilidade e interpretação da avaliação realizada, mas que pode não ser representativa da realidade medida). Entre as consequências conhecidas, podem destacar-se o aparecimento da visão de túnel, isto é, o grande enfoque no que é medido em detrimento de outras vertentes do desempenho hospitalar, a sub-optimização, que aparece quando alguns agentes se esforçam para a prossecução de objetivos setoriais, por vezes desalinhados dos organizacionais, ou a miopia, inerente à concentração em objetivos de curtoprazo, que são mais facilmente medíveis (Simões, 2004). Estes problemas podem e devem ser combatidos, nomeadamente recorrendo-se a processos que permitam envolver o pessoal avaliado no desenvolvimento e implementação dos indicadores do sistema de avaliação, flexibilizando a sua utilização e quantificando, sempre que possível, os objetivos a atingir.

\subsection{A Motivação para um Benchmarking aos Hospitais Portugueses}

Existem diversos modelos de avaliação para os hospitais. Dependendo do país e da existência ou não de um Serviço Nacional de Saúde, a forma como se 
avalia e mesmo o tipo de indicadores utilizados pode variar. Os indicadores são usualmente agrupados em três dimensões da avaliação da qualidade da atividade hospitalar: estrutura, processos e resultados (Donabedian, 1980). No entanto, algo é comum às avaliações feitas pelos Estados (e pelas empresas de acreditação e benchmarking que lhes prestam serviços), no que toca à avaliação de resultados. Nestas avaliações não é usual utilizarem-se metodologias de fronteira para avaliar o desempenho dos hospitais, preferindose uma avaliação baseada numa longa lista de indicadores, sem se conseguir obter uma imagem única e direta da realidade hospitalar. Isto fica bem patente ao analisar-se os relatórios de retorno enviados pela ACSS aos hospitais do SNS, na longa lista pública de indicadores usados pelo National Health System britânico e pela proliferação de empresas que prestam serviços de acreditação e benchmarking: a IASIST, em Portugal, Espanha e Reino Unido, a Caspe Health Knowledge System (CHKS) e a Dr. Foster, no Reino Unido, ou a Thomson Reuters, que publica o 100 Top Hospitals, nos Estados Unidos da América, entre tantas outras. As metodologias de fronteira são, no entanto, largamente utilizadas pela comunidade académica (Hollingsworth, 2008).

Tendo em conta que não existe uma referência absoluta de desempenho hospitalar, considera-se oportuna e valiosa qualquer ferramenta que permita avaliar os hospitais, comparando-os entre si. Um modelo de DEA pode ser um elemento fundamental na identificação das melhores práticas e na deteção das maiores fontes de ineficiência, agregando múltiplas variáveis que caracterizem a produção hospitalar, para que se obtenha uma imagem global e agregada de um hospital. Neste estudo apresenta-se um modelo para a avaliação da eficiência hospitalar ao nível dos serviços, com esta finalidade. Para uma avaliação completa, falta realizar a avaliação da eficácia, elemento fundamental numa avaliação hospitalar. Esta avaliação será alvo de trabalhos futuros.

Por fim, é de realçar a importância política que o benchmarking hospitalar começa a ganhar em Portugal, oficializada no memorando acordado entre o Estado português e a Troica, que negociou a sua ajuda externa. Neste memorando encontra-se um pacote de medidas que o Estado se comprometeu a executar, nomeadamente o estabelecimento de um sistema de benchmarking hospitalar (Banco Central Europeu et al., 2011, ponto 3.75). 
2. Data Envelopment Analysis - Uma Metodologia para Avaliação de Eficiência e Realização de Benchmarking aos Hospitais

\subsection{Definição de Benchmarking}

Para avaliar o desempenho dos hospitais portugueses é necessário definir um padrão. Como organizações humanas complexas, os hospitais têm, usualmente, o seu padrão definido com base na análise comparativa (ou benchmarking) das unidades a avaliar. Para Camp (1989, 12), benchmarking significa "a procura das melhores práticas de uma indústria que levam a um desempenho superior". Quando aplicado ao setor público, esta técnica tem em vista a melhoria da qualidade dos serviços prestados, assim como a sua eficiência. Desde a década de 80 que esta prática tem vindo a crescer, em especial no setor da saúde, impulsionada pelas reformas realizadas no setor público, nomeadamente no Reino Unido e nos Estados Unidos da América ou em países escandinavos (Triantafillou, 2007).

Apesar de alguma controvérsia e dificuldades inerentes ao processo de benchmarking (Triantafillou, 2007), são bastantes as virtudes que the são atribuídas. Em primeiro lugar, realizar benchmarking implica criar referências quantitativas comuns, que não se baseiam em opiniões ou valores, mas sim em medidas concretas de produtividade. A partir destas referências, a experiência sugere que um mecanismo quase automático é iniciado, já que a comparação insta, de facto, as organizações a agir (Triantafillou, 2007). Ao compararem-se com os seus pares, as organizações assumem o papel de sujeitos que buscam o seu próprio aperfeiçoamento e tentam implementar mudanças organizacionais, de procedimentos ou de gestão que as levem à superação de si mesmas. Outros autores referem que o benchmarking permite a melhoria do desempenho de uma organização, através da identificação direta de práticas e de objetivos a serem atingidos e de uma maior perceção das suas forças e fraquezas (Voss et al., 1997).

\subsection{Definição de Eficiência}

O desempenho de uma unidade está intimamente ligado à sua produtividade, que é definida como o rácio entre a produção por si obtida (o 
output) e os recursos para tal utilizados (o input). Numa indústria, ou conjunto de unidades, a produtividade raramente é igual para todos os seus elementos. A variação resulta, usualmente, das diferenças na tecnologia de produção, na escala das operações, na eficiência operacional e no ambiente operacional no qual a produção ocorre (Fried et al., 2008). Enquanto o último fator é exógeno ao gestor de uma unidade de produção, os restantes encontram-se diretamente ligados à sua atuação. Ainda assim, a que será mais facilmente manipulável pelo gestor será mesmo a eficiência operacional, medida como o rácio entre o output obtido e o máximo teoricamente possível, para a tecnologia utilizada, dado um certo nível de inputs (perspetiva dos outputs), ou entre o input mínimo e o utilizado, para obter um dado nível de outputs (perspetiva dos input). No entanto, esta medição de eficiência esbarra num grande problema: como aferir o verdadeiro potencial produtivo de uma unidade. Não se tratando de uma reação química nem de uma máquina, mas sim de uma organização humana, inerentemente complexa e com uma imprevisibilidade associada, a única maneira de aferir este potencial reside no que é conhecido ou é observável na indústria, naquilo que pode ser denominado de fronteira das melhores práticas. É nesta definição de um padrão real que entra o conceito de benchmarking numa avaliação de eficiência, tida como uma medida de distância às melhores práticas observadas, ou como uma produtividade relativa. Por isto mesmo, é fundamental avaliar-se a eficiência de uma organização para se identificar o que é possível melhorar, com que extensão pode isto ser feito, e para se controlar a própria produção, tendo em vista melhores resultados.

Koopmans (1951) apresentou o conceito de unidade produtiva tecnicamente eficiente: uma unidade é tecnicamente eficiente se um aumento num qualquer output implicar a redução de um outro output ou o aumento de pelo menos um dos inputs (ou vice-versa) (Fried et al., 2008). Isto é, uma unidade é tecnicamente eficiente se se situar sobre a fronteira das melhores práticas da indústria. Para unidades ineficientes, a medida de eficiência é uma medida da distância do produtor à fronteira do conjunto de possibilidades produtivas (distância essa calculada, de acordo com Farrell (1957), seguindo a linha que liga a origem à fronteira, passando pela unidade ineficiente). É a medição da eficiência técnica, possível através das técnicas descritas de 
seguida, que se tomará como aferidora do desempenho de uma unidade hospitalar.

\subsection{Técnicas de Medição de Eficiência - DEA vs. SFA}

Como resulta da definição da secção anterior, medir a eficiência envolve sempre a comparação do desempenho de uma unidade com o de uma outra, localizada na fronteira de produção da amostra considerada. Historicamente, estas técnicas classificam-se em paramétricas e não-paramétricas. As primeiras baseiam-se na criação de uma função de produção uni-produto (ou output) ou uni-recurso (ou input) e identificam duas possíveis causas de desvio da fronteira: a casualidade (ou ruído estatístico) e a ineficiência técnica. Para incorporarem estas duas fontes de desvio, os modelos utilizam dois termos estocásticos. Estes modelos pertencem à família denominada de Stochastic Frontier Analysis (SFA), que permite distinguir a magnitude dos dois efeitos, com a contrapartida da assunção de distribuições específicas para os erros e assumindo que estes mesmos erros são independentes entre si. Os métodos não-paramétricos, que incluem a técnica de Data Envelopment Analysis (DEA), baseiam-se em modelos de programação matemática que têm por objetivo modelar as fronteiras de produção como segmentos lineares, sem incorporarem formas de avaliar estatisticamente os erros inerentes a uma medição da realidade (Fried et al., 2008). Estes métodos permitem o estudo de unidades com múltiplos inputs e outputs.

Ambas as técnicas apresentam uma semelhança: baseiam-se na estimação da fronteira de produção e num exercício de benchmarking rigoroso, já que exploram funções de distância entre as diferentes unidades e as suas projeções sobre a fronteira eficiente. No entanto, as diferenças são várias. A formulação original do DEA não incorpora o erro estatístico impossibilitando a distinção do que é, de facto, falta de eficiência do que é casualidade ou ruído estatístico (possibilidade existente no SFA), sendo, por isso, esta técnica muito sensível a observações extremas (a sua maior fragilidade). Como é uma abordagem nãoparamétrica, não é necessário fazer grandes assunções a priori, sendo de destacar a ausência de imposições relativas à forma da fronteira de produção e à distribuição dos erros. Desta forma, com o DEA não se corre o risco de 
confundir a falta de eficiência com uma simples má especificação da forma funcional do modelo, ao contrário da utilização do SFA. Enquanto o SFA baseia a medição de eficiência numa comparação com uma fronteira teórica estimada, o DEA mede a eficiência relativamente a uma fronteira que envolve todas as unidades produtivas que foram observadas na prática. Para que isto aconteça, no DEA realiza-se uma otimização por cada unidade em estudo, enquanto no SFA se realizam apenas dois passos, estimando-se a fronteira no primeiro e calculando-se a distância da unidade a esta fronteira no segundo. Isto faz com que seja mais fácil analisar individualmente cada unidade utilizando o DEA, enquanto é mais fácil obter a informação relativa a toda a amostra usando o SFA, o que torna esta ferramenta mais útil para analisar políticas de saúde do que dar informação de gestão aos gestores hospitalares ou aos seus financiadores, como o faz o DEA (O'Neill et al., 2008).

Neste trabalho é escolhida a utilização da metodologia DEA, por ser a que melhor se adapta à multiplicidade de recursos e produtos existentes na atividade hospitalar, e por permitir uma exploração da fronteira de eficiência sem se fazer uma assunção da sua forma funcional.

\subsection{Data Envelopment Analysis}

O Data Envelopment Analysis (DEA) é uma metodologia que permite não só tratar a complexidade inerente à comparação entre unidades que apresentem multiplicidade de inputs e outputs, como permite agregar numa única medida os resultados desta comparação complexa. O resultado do DEA é uma medida de eficiência para cada unidade de decisão (em inglês Decision Making Unit ou DMU), calculada com base na comparação dessa mesma unidade com uma ou várias unidades de referência, com o melhor desempenho observado.

Como esta metodologia é baseada num cálculo de produtividade assente em múltiplos inputs e outputs, existe a necessidade de atribuir pesos distintos a cada um desses itens, de forma a evidenciar a importância relativa de cada um deles. Para eliminar arbitrariedades, o método consiste no cálculo da produtividade relativa (ou eficiência) de cada DMU, com os pesos que mais a beneficiam. Na prática, isto é realizado maximizando-se o rácio (1), sujeito às 
restrições (2) e (3). Este programa fracional é o modelo que está na base desta metodologia e é denominado modelo CCR, após a apresentação por Charnes, Cooper e Rhodes (1978) do estudo considerado a origem do DEA. Neste programa, aplicado a cada uma das unidades em estudo, considera-se existir $n$ unidades em avaliação, $m$ inputs e $s$ outputs, sendo o a unidade em estudo (Cooper et al., 2007, 23).

$$
\begin{array}{cl} 
& \max _{v, u} \theta=\frac{\sum_{r} u_{r} y_{r o}}{\sum_{i} v_{i} x_{i o}} \\
\text { Sujeito a: } & \frac{\sum_{r} u_{r} y_{r j}}{\sum_{i} v_{i} x_{i j}} \leq 1 \quad(j=1, \cdots, n) \\
& v_{\mathrm{i}}, u_{r} \geq 0 \quad(\forall i, r)
\end{array}
$$

É a imposição das restrições em (2) que torna o resultado uma medida da eficiência de cada unidade, já que, ao limitar o resultado que cada uma pode obter, está a criar-se uma referência relativamente à qual todas as unidades se irão comparar. O lado esquerdo da inequação (2) tomará o valor de 1 se a unidade em causa for uma unidade de referência. As unidades de referência encontradas durante a otimização são aquelas cujos pontos representativos formam a fronteira da produção. Quando comparada com a fronteira de produção, cada DMU escolhe os pesos a atribuir a cada input e output, de forma a maximizar o seu resultado de eficiência. Assim sendo, quando uma unidade apresenta um resultado de eficiência inferior à unidade, isto significa que ela é, de facto, ineficiente. Por fim, há que referir que as unidades em estudo devem ser homogéneas, isto é, ter características e comportamentos semelhantes. A introdução no modelo de elementos não controláveis pela gestão (elementos não-discricionários), permite homogeneizar as unidades sujeitas a elementos exógenos não controláveis.

Na prática, a metodologia de DEA utiliza um modelo de programação linear para calcular as eficiências de cada uma das unidades em estudo. A linearização do modelo anterior, numa perspetiva orientada aos inputs, leva à alteração da função objetivo (1) para a (4), dando origem à restrição (5). A linearização transforma a restrição (2) na (6), mantendo-se a restrição de não- 
negatividade dos pesos. Esta formulação do DEA é designada "modelo dos pesos".

$$
\begin{array}{ll} 
& \max _{v, u} \theta=\sum_{r} u_{r} y_{r o} \\
\text { Sujeito a: } & \sum_{i} v_{i} x_{i o}=1 \\
& \sum_{r} u_{r} y_{r j}-\sum_{i} v_{i} x_{i j} \leq 0 \quad(\mathrm{j}=1, \cdots, n) \\
& v_{\mathrm{i}}, u_{r} \geq 0 \quad(\forall i, r)
\end{array}
$$

A nova função objetivo consiste na maximização do numerador do rácio de produtividade, continuando as variáveis de decisão a ser os pesos dos inputs e outputs. Como referido atrás, este é o modelo CCR e as suas principais características prendem-se com a assunção de rendimentos constantes à escala, isto é, a existência de uma variação proporcional dos outputs face a uma variação dos inputs. Se na situação em estudo os aumentos de outputs não forem proporcionais aos aumentos de inputs (rendimentos variáveis à escala), deve corrigir-se o modelo anterior, alterando-se a função objetivo e a restrição (6):

$$
\begin{array}{ll} 
& \max _{v, u} \theta=\sum_{r} u_{r} y_{r o}-w \\
\text { Sujeito a: } & \sum_{i} v_{i} x_{i o}=1 \\
& \sum_{r} u_{r} y_{r j}-\sum_{i} v_{i} x_{i j}-w \leq 0 \quad(\mathrm{j}=1, \cdots, n) \\
v_{\mathrm{i}}, u_{r} \geq 0 \quad(\forall i, r) \\
\mathrm{w} \in \mathfrak{R}
\end{array}
$$

Um avaliação de eficiência assumindo rendimentos variáveis à escala faz com que cada unidade seja avaliada relativamente a unidades de dimensão mais semelhante à sua, dando origem a uma fronteira que restringe mais o conjunto de possibilidades produtivas. O modelo que assume rendimentos variáveis à escala denomina-se BCC (do trabalho original de Banker, Charnes e 
Cooper (1984)). O que há de comum entre este modelo e o CCR é a medição radial da eficiência que ambos realizam. Em ambos, a medida de eficiência obtida representa o fator pelo qual cada unidade deve multiplicar os seus inputs, de modo a situar-se sobre a fronteira de produção, isto é, sem alterar o seu mix (proporção) de inputs (ou de outputs para a orientação alternativa).

Existem outras variantes aos modelos básicos de DEA. Uma delas, que será usada neste estudo, consiste na introdução de restrições aos valores dos pesos. Esta variante é utilizada quando se pretende impor ao modelo características resultantes de um julgamento a priori do avaliador, que o torne mais realista, ou mesmo quando se pretende simplesmente analisar o impacto da escolha destes pesos de entre um determinado conjunto de valores (análise de sensibilidade). Uma das formas de impor este tipo de restrições consiste na utilização do método da região de confiança (traduzido do inglês Assurance Region Method, proposto por Thompson et al. (1986)), em que se restringe o valor dos rácios entre os pesos de inputs (ou outputs) distintos, de forma a enquadrar a relação entre ambos com um limite inferior $(\alpha)$ e superior $(\beta)$ (Thanassoulis et al., 2004):

$$
\alpha \leq \frac{v_{2}}{v_{1}} \leq \beta
$$

Estas restrições poderiam ser também aplicadas aos pesos virtuais dos inputs e outputs, isto é, o produto do valor de cada variável com os respetivos pesos. De facto, são os pesos virtuais que representam a verdadeira importância de cada input e output no valor calculado da eficiência de uma unidade. Contudo, a sua utilização implica, de forma indireta, uma limitação absoluta dos pesos do modelo e não um enquadramento relativo, como o realizado com (13) (Thanassoulis et al., 2004), gerando por vezes problemas na otimização do modelo. A colocação da equação (13) no "modelo dos pesos", sob a forma de duas restrições e consequente linearização, altera a fronteira eficiente, diminui o domínio do modelo de programação linear. Como consequência, as unidades veem a sua eficiência piorar ou manter-se, face ao modelo sem restrições de pesos. Também é possível que a referência com que 
a DMU em avaliação é comparada, correspondente ao objetivo de desempenho proposto pelo modelo, tenha, para um ou mais inputs, valores superiores ao da DMU avaliada (e vice-versa na orientação para outputs).

\subsection{A Utilização do DEA na Avaliação de Hospitais}

\subsubsection{Processo de Produção Hospitalar}

$\mathrm{Na}$ avaliação de cuidados médicos, especialmente em hospitais ou unidades de cuidados primários, existem duas perspetivas de análise: uma ligada à gestão, que é responsável pela afetação dos recursos necessários à atividade clínica, e outra ligada ao tratamento dos pacientes, que se designa por perspetiva clínica, seguindo Chilingerian e Sherman (2004). Como pode ver-se na Figura 1, as perspetivas estão interligadas, já que os outputs da primeira coincidem com os inputs da segunda (elementos denominados de outputs intermédios). No entanto, enquanto na primeira perspetiva uma gestão eficiente terá como objetivo minimizar o input, para um dado nível de output intermédio (a capacidade instalada e disponibilizada ao médico), na segunda o tratamento clínico adequado dos doentes preocupa-se com a maximização dos outcomes positivos no estado da saúde dos indivíduos, que refletem os resultados finais sobre a sua saúde. Usando DEA, podemos calcular uma medida de desempenho em ambos os casos, sendo que no primeiro denominamos essa medida como eficiência e no segundo como eficácia. A responsabilidade pelo desempenho em cada um dos casos é diferente, já que a eficácia é controlada pelo médico, enquanto a eficiência é controlada pelo gestor.
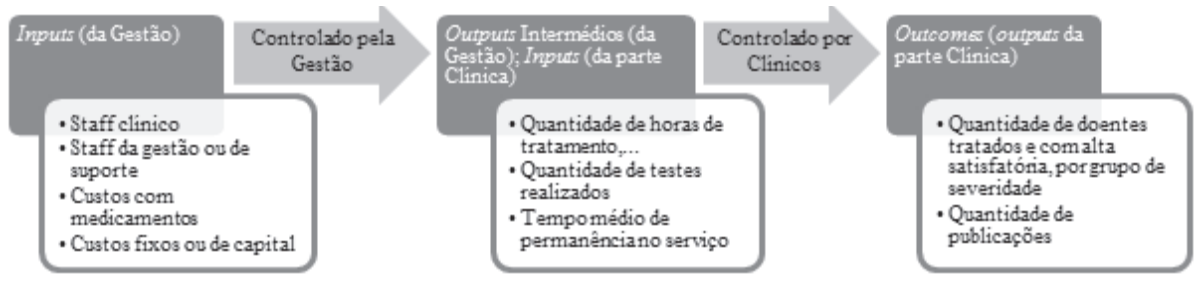

Figura 1 - Duas Perspetivas da Atividade Hospitalar (Chilingerian e Sherman, 2004, 496). 
Para um estudo numa perspetiva de eficiência das unidades hospitalares usando DEA, não existe um modelo globalmente aceite relativamente aos inputs e outputs intermédios a considerar. A escolha deve ser feita de forma a adequar, o melhor possível, o modelo à realidade a estudar. Os inputs devem ser categorizados em grupos que façam sentido para os gestores que os controlam e que representem a maior parte dos gastos pelos quais são responsáveis. Quanto aos outputs, eles só estarão bem definidos se entrarem em linha de conta com a complexidade dos tratamentos realizados pelas unidades estudadas.

A perspetiva da eficácia clínica, não abordada neste trabalho, tem sido estudada limitando os resultados dos pacientes ao seu estado na alta, como vivo ou morto (Castro, 2011). Sendo esta uma visão simplista do assunto, o estudo do desempenho clínico de especialidades médicas concretas pode vir a alterar este paradigma. Esta é a perspetiva que apresenta maiores dificuldades de avaliação e que, por isso, apresenta o maior número de oportunidades para a aplicação de técnicas de fronteira para a avaliação do desempenho.

\subsubsection{Utilização do DEA na Avaliação do Desempenho Hospitalar}

O DEA é a metodologia mais usada em estudos de desempenho em saúde e são os hospitais, por larga margem, os alvos preferenciais destes mesmos estudos (Hollingsworth, 2008). Estes estudos tentam avaliar a eficiência destas organizações complexas, onde não existe um modelo de produção globalmente aceite e onde, por isso, as avaliações com DEA poderão ser muito sensíveis a erros de medição ou a uma fraca aferição da realidade, por omissão consciente ou inconsciente de variáveis (Hollingsworth et al., 1999). É por isto mesmo que se defende que a utilização de DEA numa avaliação de hospitais deveria cingir-se a aferir tendências gerais ou a avaliar unidades mais pequenas e concretas, como por exemplo serviços ou mesmo práticas médicas, onde os potenciais erros de medição serão menores. Os hospitais não são, por isso, considerados unidades suficientemente homogéneas para permitirem a utilização simples e direta desta técnica, apesar da literatura se centrar no seu estudo. 
Ao contrário da literatura de avaliação de hospitais, que é vasta, a literatura de avaliação de unidades sub-hospitalares não o é. Os estudos de Puig-Junoy (1998) e Kontodimopoulos e Niakas (2005) são exemplos de análises feitas a este nível com recurso ao DEA. No primeiro caso, o estudo tenta discernir o que determina o desempenho de unidades de cuidados intensivos. Este estudo concluiu pela maior relevância do fator "procedimentos médicos utilizados" para a eficiência destas unidades, em detrimento da gravidade ou complexidade das doenças diagnosticadas, evidenciando uma ligação entre eficiência e decisões clínicas, o que sublinha a importância de se aferir o impacto dos cuidados sobre a saúde dos pacientes. O segundo trabalho estuda unidades de hemodiálise gregas, e discute as dificuldades de análise de unidades sub-hospitalares usando DEA. Neste estudo, a validade dos resultados é limitada pelo reduzido número de variáveis consideradas, o que se deve à parca informação disponibilizada por parte dos prestadores de cuidados e das autoridades governamentais.

Em Portugal, encontram-se estudos semelhantes a estes, como os que avaliam Grupos de Diagnósticos Homogéneos (GDH). Como exemplo destes estudos, pode destacar-se o de Dismuke e Sena (2001) que, tendo por base os dois mais frequentes GDH (o das desordens cerebrovasculares, exceto ataques isquémicos transitórios, e o das falhas e ataque cardíacos) estudaram a evolução da produtividade de 3 tecnologias de diagnóstico, a TAC (tomografia axial computorizada), o eletrocardiograma e o ecocardiograma, ao longo de 3 anos (1992 a 1994). Estes estudos avaliaram se o aumento de produtividade nestas tecnologias trouxe consigo uma diminuição da qualidade, aferida pela mortalidade. Utilizando um modelo de DEA com outputs indesejáveis e os índices de Malmquist-Luenberger (usados para aferir a evolução da produtividade), verificou-se que não havia evidência de que o aumento da eficiência tenha provocado uma diminuição da qualidade, medida através da taxa de mortalidade.

A maioria dos estudos sobre hospitais não chega a aferir o impacto que os cuidados de saúde têm na melhoria real da condição dos doentes. É frequente usar-se, como medidas de output, variáveis que aferem apenas o resultado do processo produtivo hospitalar, como dias de permanência em internamento, 
total de altas médicas ou número de consultas externas. Uma percentagem reduzida dos estudos utiliza medidas de resultado efetivo como a taxa de mortalidade ou a qualidade dos cuidados individuais prestados (Hollingsworth, 2008; O'Neill et al., 2008). Como exemplo destes estudos, pode citar-se o caso Nayar e Ozcan (2008). Avaliando hospitais do estado da Virgínia nos EUA, o estudo tenta descobrir qual o impacto sobre a medida de eficiência dos hospitais, de variáveis de qualidade nos outputs. Deste estudo surgiu evidência de que os hospitais tecnicamente eficientes eram também aqueles que apresentavam bons resultados em termos de qualidade de cuidados. No entanto, esta conclusão é enviesada, por ser uma consequência quase direta da metodologia usada, em que se consideraram as perspetivas de eficiência e eficácia simultaneamente.

A aplicação do DEA ao setor hospitalar usa tradicionalmente uma orientação para inputs, justificando-se este facto pela predominância da perspetiva da eficiência na avaliação hospitalar (Figura 1). Isto resulta da preocupação que os diferentes agentes da saúde têm na contenção de recursos, uma vez que a produção hospitalar é, essencialmente, ditada pela procura da população, um fator exógeno ao hospital. Nesta categoria, as variáveis mais utilizadas correspondem ao número de camas, número de médicos, enfermeiros, outros funcionários ou mesmo os custos que estas categorias profissionais representam, assim como os custos com consumíveis (medicamentos e material clínico, principalmente) (Castro, 2011). ${ }^{1}$ A maioria dos estudos analisa a eficiência técnica e, tendo em vista uma homogeneização de outputs, utilizam-se variáveis que fazem referência à complexidade dos doentes tratados (case-mix) ou ao número de serviços dos hospitais (servicemix). Devido à inexistência de um modelo de produção globalmente aceite, bem como à heterogeneidade da atividade hospitalar em contextos distintos, não há consenso relativamente ao tipo de rendimentos à escala que deverá ser assumido nas análises, optando-se muitas vezes pelo uso dos dois modelos e posterior comparação.

\footnotetext{
${ }^{1}$ Em países como Portugal, onde a existência de longas listas de espera é um problema, poder-seia optar por uma orientação para os outputs, identificando-se, assim, formas para aumentar a produtividade dos hospitais no lado da produção.
} 
Em Portugal, a atividade avaliativa tem vindo a ser objeto de atenção crescente e centrou-se, principalmente, nas recentes transformações que o setor da saúde tem sofrido. Mais recentemente, utilizou-se o DEA em grande medida, ao nível dos hospitais, para avaliar a reforma da transformação dos hospitais públicos em Sociedades Anónimas (SA). Deste universo, podem destacar-se os estudos do Tribunal de Contas (2006), de Moreira (2008) e de Gonçalves (2008). O primeiro tinha por objetivo medir a eficiência económica dos hospitais transformados e medir a qualidade e equidade no acesso aos cuidados de saúde. Só no estudo da eficiência económica se utilizou o DEA. Como conclusões, destaca-se a evidência de diferenças nos níveis de eficiência, quando se comparam os hospitais SA com os do Setor Público Administrativo (SPA) de dimensão semelhante, embora sem resultados totalmente consistentes. Em Moreira (2008), utilizou-se o grupo dos hospitais SPA como um grupo de controlo, criando-se dois tipos de fronteiras. As conclusões, baseadas em dados de 2001 a 2005, apontam para uma maior eficiência média inicial no grupo dos hospitais SPA, o que se reverteu no ano de 2005. Recorrendo à evolução temporal dos valores de eficiência, a análise permitiu identificar uma maior evolução (ligeira, porque as diferenças iniciais eram também ligeiras) dos hospitais SA face aos SPA, em termos médios. O estudo de Gonçalves (2008) obteve um resultado contrário. Utilizando dados referentes ao período entre 2002 e 2004, Gonçalves (2008) verificou, usando os Índices de Malmquist, que a fronteira de eficiência técnica evoluiu positivamente neste período, tendo sido os hospitais SPA os que mais contribuíram para esta evolução, já que apresentaram crescimentos de eficiência maiores que os SA. Em suma, os estudos parecem indicar que os hospitais SA viram a sua eficiência melhorar, globalmente, mas não a um ritmo que os diferencie muito dos hospitais SPA, como esperado inicialmente. Em conjunto, os estudos apresentam evidência da inadequação do método quando se avaliam hospitais, pela impossibilidade da definição de modelos que capturem mais fielmente a sua complexidade. Em Portugal, não existe outra avaliação que, usando DEA, se foque nos serviços dos hospitais. 


\section{Modelo Avaliativo para os Serviços Médicos/Cirúrgicos dos Hospitais do SNS} numa Perspetiva de Eficiência

\subsection{Caracterização e Escolha dos Serviços a Analisar}

A estrutura dos hospitais não é homogénea. Cada hospital tem a sua estrutura interna definida de acordo com a sua influência geográfica e, principalmente, de acordo com as valências/especialidades implementadas. No entanto, algo é comum a todos: os serviços são as suas unidades funcionais fundamentais. Existem diversas formas de agrupar os diferentes tipos de serviços de um hospital, apresentando-se aqui uma que define quatro grupos de serviços. Os serviços das especialidades médicas ou cirúrgicas ${ }^{2}$ têm a responsabilidade de servir diretamente os pacientes através de internamentos, consultas externas, sessões em hospital de dia ou cirurgias em ambulatório, quatro das cinco principais linhas de produção que um hospital realiza, como é convencionalmente aceite na literatura (falta nesta lista a linha de produção de urgência). A estes serviços podemos chamar de "Serviços Principais". Os hospitais têm também serviços responsáveis por servir de apoio clínico aos serviços anteriores, tais como o bloco operatório, os serviços médicos apenas responsáveis por meios complementares de diagnóstico e terapêutica ou a farmácia hospitalar. Também têm serviços que prestam cuidados de saúde generalizados, como o serviço de Urgência Geral. Todos estes serviços podem ser denominados "Serviços Clínicos Transversais". Para um apoio mais geral a todos os serviços hospitalares e unidades, como a limpeza ou manutenção dos edifícios, os hospitais têm ainda os denominados "Serviços de Apoio Geral". Por fim, os hospitais têm também serviços para gerir toda a sua estrutura, como o conselho de administração e o pessoal administrativo ou outros técnicos. Esses serviços podem ser agrupados nos "Serviços Administrativos". Neste trabalho, vão analisar-se os serviços principais já que, para além de serem os responsáveis pelo atendimento direto dos utentes, são eles também os responsáveis pelo maior volume de custos que se podem imputar diretamente

\footnotetext{
${ }^{2}$ Em Medicina, diferenciam-se as especialidades que são exclusivas dos cirurgiões, especialidades cirúrgicas, das que são da responsabilidade dos não-cirurgiões, especialidades médicas.
} 
a cada serviço, como pode ver-se na Figura 2, com dados dos hospitais do SNS que reportam a 2008 .

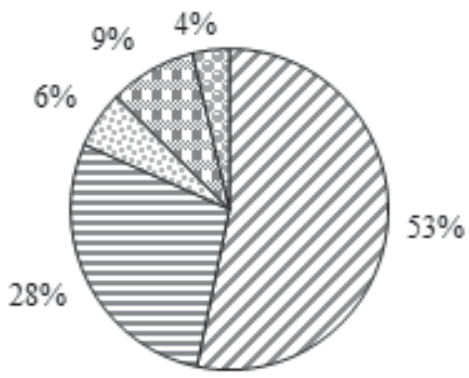

\author{
$\square$ Principais \\ 日Clinicos Transversais \\ $\square$ Apoio Geral \\ ๑Adm inistrativos \\ GCustos Não Imputáveis
}

Figura 2 - Distribuição dos Custos Diretos pelos Diferentes Grupos de Serviços.

Neste estudo apresenta-se um modelo "ideal", que tem como objetivo uma avaliação, numa perspetiva de eficiência, dos serviços principais, considerando apenas a produção das quatro principais linhas de produção. Também é nestes serviços que se realiza a maioria da produção hospitalar e é neles que são maioritariamente imputados todos os custos das restantes secções hospitalares (secções de apoio). É necessário notar que é enquanto dura um internamento que se realizam cirurgias nos pacientes internados em serviços de especialidades cirúrgicas e, por isso, a produção de cirurgias está já contemplada quando se fala em internamentos e se controla para a complexidade das doenças tratadas. Durante o internamento, o serviço pode também colocar os doentes em unidades de cuidados intensivos afetas exclusivamente ao serviço. Aqui, considerar-se-á que estas unidades fazem parte da prestação de cuidados em internamento e, como tal, os recursos utilizados em internamento contemplam os recursos usados nestas unidades especiais dos respetivos serviços, para além dos usados nas unidades mais convencionais. Posteriormente à idealização do modelo, ele será concretizado numa avaliação do serviço de Medicina Interna de hospitais do SNS, para o ano de 2008. 


\subsection{Proposta de Modelo de DEA para Benchmarking aos Serviços Hospitalares}

\section{Principais numa Perspetiva de Eficiência}

A criação do modelo deste estudo iniciou-se com uma revisão bibliográfica, que teve por finalidade identificar as variáveis mais frequentes nos estudos da área. Esta revisão pode ser consultada em Castro (2011).

Tendo em vista a identificação das variáveis que melhor caracterizam o conjunto dos recursos (inputs) utilizados pelos serviços a estudar, identificaram-se, posteriormente, as estruturas de custos médias para os serviços de especialidades médicas e para os de especialidades cirúrgicas, em todos os hospitais do SNS. As variáveis de input em causa, num modelo de aferição da eficiência técnica, podem ser escolhidas de tal forma que representem cada elemento da estrutura de custos média. Para concretizar isto mesmo, recorreu-se à informação da contabilidade de gestão de 2008, fornecida pelos hospitais à ACSS. Nesta análise, contabilizaram-se todos os custos incorridos pelas linhas de produção de internamento, consulta externa e hospital de dia, já que a ACSS não dispõe de informação relativa à discriminação dos custos com cirurgia em ambulatório pelos diferentes serviços. No entanto, esta linha de produção apresentou, em 2008, custos residuais face aos restantes.

Como pode ser visto na Figura 3, os tipos de custos mais representativos nos dois grupos de serviços são os mesmos (variando apenas o peso de cada um deles), à exceção do Bloco Operatório, não utilizado pelas especialidades médicas (não realizam cirurgias). As principais categorias de custos são, então, os custos com Pessoal (CP), Matérias Vendidas e Consumidas (CMVMC - que representam principalmente os medicamentos e o material clínico), Meios Complementares de Diagnóstico e Terapêutica (MCDT), Serviços Administrativos (SA), Fornecimentos e Serviços Externos (FSE) e Serviços Hoteleiros (SH), responsáveis por 93\% do total de custos nos serviços médicos. Aos serviços cirúrgicos, acrescenta-se o Bloco Operatório (BO) e o total destas categorias representa $94 \%$ do total.

Sendo os custos com o pessoal uma categoria bastante heterogénea, por incorporar diferentes categorias profissionais, é necessário avaliá-la de forma mais pormenorizada. Realizando uma análise semelhante à anterior, verificou- 
se que $90 \%$ e $92 \%$ dos custos com pessoal nos serviços médicos e cirúrgicos, respetivamente, são atribuíveis aos médicos, enfermeiros e ao pessoal operário e auxiliar. Estas serão, portanto, as categorias profissionais que interessará considerar como recursos, se se quiser aferir quais as que têm maior impacto nos custos e uma ação direta no funcionamento dos serviços, mantendo ainda o número de variáveis reduzido.
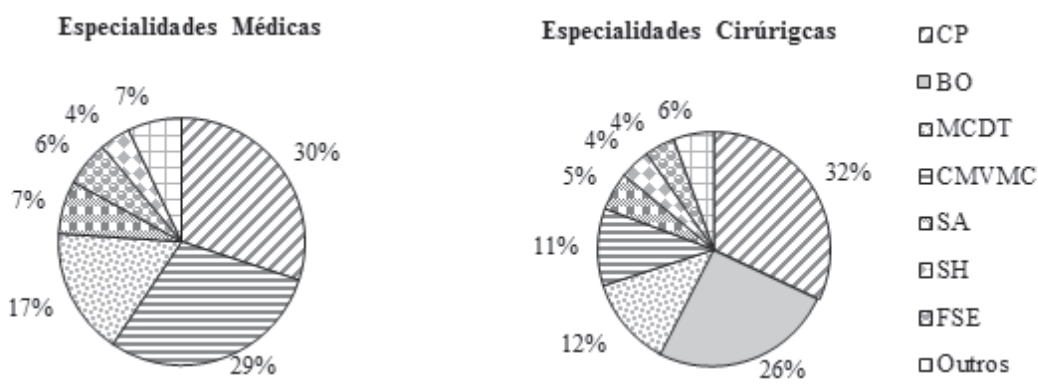

Figura 3 - Estrutura dos Custos Gerais nos Serviços Principais.

Após a análise à estrutura de custos dos serviços principais, é então possível definir uma lista de inputs e outputs que permita modelar, idealmente, o processo de utilização de recursos para disponibilizar aos clínicos a capacidade de tratar doentes (outputs intermédios). Como se pretende calcular a eficiência técnica das unidades em avaliação, definem-se todas as variáveis, de um modelo ideal, em termos de quantidades e não de valores económicos.

Para representar os recursos de pessoal, optou-se por considerar o número de horas semanais disponibilizadas pelos médicos e enfermeiros, como dois dos inputs do modelo. Como o pessoal operário e auxiliar tem um peso nos custos bastante inferior ao das classes clínicas, optou-se por representar este recurso por uma variável mais genérica. Pretendeu-se que esta variável representasse outros recursos que se possam assumir proporcionais à dimensão de um serviço. A variável escolhida foi o número de camas, muitas vezes considerada, na literatura, uma proxy para a dimensão dos serviços. Além de representar o pessoal operário, a variável "número de camas" representa, neste modelo, os custos com os FSE (muitas vezes considerados, na literatura, proporcionais à dimensão de um serviço), com os serviços administrativos e 
com os serviços hoteleiros. O número de camas é, assim, uma variável que funciona como proxy para estas quatro categorias de recursos. A alternativa a esta opção seria a consideração de mais variáveis de input, o que reduziria a discriminação do modelo, dado o tamanho da amostra de hospitais nacionais. Para atestar esta opção, verificou-se a existência de correlações significativas entre estas variáveis e o número de camas (valores entre 0,703 e 0,937), o que confirma a validade da representação destes recursos pela variável "número de camas".

Os diferentes serviços de MCDT prestam apoio aos serviços principais, o que leva à necessidade de se contabilizar os procedimentos que os últimos requerem, de forma ponderada, para refletir a diferente complexidade e imputar um maior dispêndio de recursos aos serviços que utilizem procedimentos mais complexos. O ponderador dos procedimentos é definido pelo Ministério na Portaria n. ${ }^{\circ} 839-\mathrm{A} / 2009$. Os MCDT são então representados por esta variável. Para representar os CMVMC, seria ideal contabilizarem-se os medicamentos e material clínico, de forma semelhante ao que é feito com os MCDT. Contudo, não existe uma definição de ponderadores, por parte do Ministério da Saúde, para estes elementos. Assim, na prática e por agora, não resta alternativa à utilização dos custos para a sua ponderação. Na lista de recursos apresentada abaixo permanece a variável que seria ideal utilizar (e que um dia talvez se possa utilizar), enquanto na secção seguinte, em que se demonstra a aplicação prática do modelo teórico aqui proposto, se utilizam os custos incorridos com os CMVMC, como proxy para as quantidades de matérias ponderadas usadas pelos serviços.

Para se representar os recursos gastos, pelos serviços, com o bloco operatório (BO), optou-se por escolher a variável que representa o tempo médio semanal que cada especialidade ocupa neste serviço auxiliar. Além do tempo total das intervenções, pode considerar-se o número total de intervenções como produto do BO. O número de horas que um serviço ocupou no bloco será vantajoso relativamente ao total de intervenções, por aferir, simultaneamente, a complexidade e quantidade das intervenções realizadas, considerando-se uma qualidade uniforme dos médicos. 
Por fim, é de salientar que as variáveis de recursos escolhidas, e sumariadas na Tabela 1, se referem a 89 e 92\% dos custos totais das quatro linhas de produção consideradas nos serviços de especialidades médicas e cirúrgicas, respetivamente.

Tabela 1 - Variáveis de Input dos Modelos de DEA para os Serviços Principais

\begin{tabular}{|c|c|}
\hline Nome & Definição Operacional \\
\hline $\begin{array}{l}N^{\circ} \text { Horas } \\
\text { Médicos }\end{array}$ & Contabilização do $\mathrm{n}^{\circ}$ de horas semanais de trabalho médico no serviço. \\
\hline $\begin{array}{l}\mathrm{N}^{\circ} \text { Horas } \\
\text { Enfermeiros }\end{array}$ & Contabilização do $\mathrm{n}^{\circ}$ de horas semanais de trabalho enfermeiro no serviço. \\
\hline $\begin{array}{l}\mathrm{N}^{\circ} \text { Exames } \\
\text { Ponderados }\end{array}$ & $\begin{array}{l}\text { Contabilização do } \mathrm{n}^{\circ} \text { de procedimentos de MCDT requeridos pelo serviço, } \\
\text { ponderados pelos fatores definidos na Portaria n }{ }^{\circ} 839-\mathrm{A} / 2009 \text { do Ministério } \\
\text { da Saúde: soma do total de procedimentos multiplicados pelos seus } \\
\text { ponderadores. }\end{array}$ \\
\hline $\begin{array}{l}\mathrm{N}^{\circ} \text { Matérias } \\
\text { Ponderadas }\end{array}$ & $\begin{array}{l}\text { "Contabilização" do n }{ }^{\circ} \text { ponderado de medicamentos e materiais clínicos } \\
\text { utilizados pelo serviço. }\end{array}$ \\
\hline $\mathrm{N}^{\circ}$ Camas & Contabilização do $\mathrm{n}^{\circ}$ de camas existentes no serviço. \\
\hline $\begin{array}{l}\mathrm{N}^{\circ} \text { Horas de } \\
\text { Bloco }\end{array}$ & $\begin{array}{l}\text { Contabilização do } \mathrm{n}^{\circ} \text { de horas totais das intervenções cirúrgicas realizadas sob } \\
\text { a responsabilidade do serviço. }\end{array}$ \\
\hline
\end{tabular}

Relativamente às variáveis de output, a sua escolha deve refletir o que é fundamental ser medido: o que é produzido pelas diferentes linhas de produção. Nisto incluem-se o número total de doentes atendidos em cada linha de produção, que pode também ser considerado uma medida de acesso aos cuidados de saúde, e a quantidade total de tratamento produzido e disponível para todos os utentes, medida usualmente pelo número de unidades pelas quais se pode dividir cada tipo de tratamento (proxies desta quantidade). O número de doentes atendidos, em internamento, é usualmente contabilizado pelo número de altas num ano, em consulta externa, pelo número de primeiras consultas e, em hospital de dia, pela contabilização direta do número de doentes. O número de cirurgias em ambulatório reflete o número de doentes atendidos e as quantidades totais de tratamento produzidas, já que apenas se considera um novo doente sempre que se realiza uma nova cirurgia. Quanto ao total de tratamento produzido nas restantes linhas, ele é usualmente medido, para o internamento, pelo número de dias total que os doentes de um serviço permaneceram internados, para as consultas, pelo total de consultas realizadas (a soma das primeiras com as consultas de acompanhamento) e, 
para o hospital de dia, pelo número total de sessões a que todos os utentes tiveram acesso, tudo num determinado período de tempo. Todos estes outputs encontram-se sumariados na Tabela 2.

Tabela 2 - Variáveis de Output do Modelo de DEA para os Serviços Principais

\begin{tabular}{ll}
\hline \multicolumn{1}{c}{ Nome } & \multicolumn{1}{c}{ Definição Operacional } \\
\hline Tempo Estadia Total & $\begin{array}{l}\text { Soma do } \mathrm{n}^{\circ} \text { de dias de estadia dos pacientes que saem do } \\
\text { internamento. }\end{array}$ \\
\hline $\begin{array}{l}\mathrm{N}^{\circ} \text { Altas Internamento (com } \\
\text { correção pelo case-mix) }\end{array}$ & $\begin{array}{l}\text { Contabilização do } \mathrm{n}^{\circ} \text { total de altas de internamento } \\
\text { ponderadas pelos índices de case-mix do serviço: soma do } \\
\text { total de altas multiplicadas pelo índice de case-mix do serviço. }\end{array}$ \\
\hline $\mathrm{N}^{\circ}$ de Consultas Externas & Contabilização do $\mathrm{n}^{\circ}$ de consultas externas do serviço. \\
\hline $\mathrm{N}^{\circ}$ 1 as consultas & Contabilização do $\mathrm{n}^{\circ}$ de primeiras consultas \\
\hline $\mathrm{N}^{\circ}$ Sessões Hospital de Dia & $\mathrm{N}^{\circ}$ total de sessões de Hospital de Dia. \\
\hline $\mathrm{N}^{\circ}$ Utentes Hospital de Dia & $\begin{array}{l}\text { Contabilização do } \mathrm{n}^{\circ} \text { de doentes que tiveram acesso a sessões } \\
\text { de hospital de dia do serviço. }\end{array}$ \\
\hline $\mathrm{N}^{\circ}$ Cirurgias Ambulatório & Contabilização do $\mathrm{n}^{\circ}$ de cirurgias em ambulatório do serviço \\
(com correção pelo case-mix $)$ & ponderadas pelo respetivo índice de case-mix. \\
\hline
\end{tabular}

Ao medir ambas as dimensões da produção, comparando duas unidades com o mesmo nível de inputs e de produção em quantidade (com os mesmos dias de doentes em internamento), a que apresente o menor acesso de pessoas aos cuidados (menor número de altas), apresenta-se como uma unidade mais ineficiente. No entanto, a um fraco acesso aos cuidados de saúde proporcionado por um hospital (baixo número de altas, por exemplo), pode estar associada uma maior complexidade das doenças que este trata, o que faz prolongar a estadia de um só doente. Para controlar esta heterogeneidade das doenças, utiliza-se aqui a variável mais comum e a única disponível em Portugal: o índice de case-mix. Os índices determinam-se calculando o rácio entre o número de doentes equivalentes (definição na Circular Normativa N. ${ }^{\circ}$ 3/2008 do Ministério da Saúde) ponderados pelos pesos relativos dos respetivos GDH definidos na Portaria n. ${ }^{\circ} 839-\mathrm{A} / 2009$ do Ministério da Saúde, que refletem as diferenças inerentes às doenças. Este índice apenas pode ser calculado para o internamento e para as cirurgias em ambulatório, porque estas são as únicas linhas para as quais existe um registo e determinação de ponderadores, efetuada pelo Ministério da Saúde. O índice não é usado como 
um output per se, mas como um fator de ajuste, multiplicando-se o seu valor pela variável a ajustar.

É também de sublinhar que, aquando da implementação aos diferentes serviços (concretos), será necessário verificar a existência ou a validade de algumas das variáveis da Tabela 2 .

\subsection{Descrição do Procedimento de Implementação do Modelo}

Concretizou-se, neste estudo, um modelo piloto para avaliar o desempenho do serviço de Medicina Interna. Além de ser o segundo serviço principal mais dispendioso, lida com os casos mais comuns e é o que existe num maior número de hospitais. Para este serviço médico, o modelo "ideal” tem como variáveis de input, o " $\mathrm{N}^{\mathrm{O}}$ de Horas de Médicos", o "No de Horas de Enfermeiros", o "No de Exames Ponderados", o " $\mathrm{N}^{\circ}$ de Matérias Ponderadas" e o "No de Camas". Quanto aos outputs, sendo esta uma especialidade onde não existe produção em hospital de dia nem de cirurgias, serão relevantes as variáveis do modelo "ideal" "Tempo Estadia Total", "No Altas Internamento",

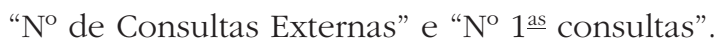

Ao tentar implementar o modelo exemplificativo, encontramos dificuldades na obtenção de alguns dados e na fiabilidade de outros. Por esse motivo, entende-se este trabalho como um guião para a implementação prática do modelo proposto e uma exemplificação do cálculo da eficiência dos diferentes serviços dos hospitais, sem se ambicionar alcançar uma imagem absolutamente fidedigna da realidade aqui avaliada (para uma discussão aprofundada do assunto, consultar Castro (2011)). Para além disto, para construir o modelo apresentado na secção anterior, não foi possível obter atempadamente alguns dados, nomeadamente o índice de case-mix do serviço de Medicina Interna, a quantidade de MCDT ponderados consumidos e as horas de trabalho de enfermeiros, embora esta informação seja recolhida pela ACSS. Devido a estas restrições, foram utilizados os custos incorridos pelos serviços com os enfermeiros, com os exames ponderados e com as matérias ponderadas, como proxy para as quantidades em falta. Para se calcular o custo com os enfermeiros somou-se o seu salário de base aos benefícios imputados ao pessoal do serviço, de forma proporcional. Para as matérias ponderadas 
somaram-se os custos com medicamentos e material clínico e para os exames ponderados somaram-se os custos com todos os MCDT incorridos pelos serviços em estudo. O índice de case-mix usado foi o índice para as especialidades médicas de cada hospital ${ }^{3}$.

Contabilizaram-se 54 hospitais que apresentaram dados para o serviço em análise (hospitais que têm, de facto, esta valência), mas apenas 48 foram avaliados. Estes hospitais fazem parte do universo dos 59 hospitais públicos do SNS para os quais a ACSS disponibilizou os dados. Em 2008, havia mais 7 hospitais no SNS mas, por diversos motivos, a ACSS não possuía informação sobre eles. Foram eliminados da amostra os hospitais que apresentavam falhas em qualquer das variáveis, quer por valores em falta, quer terem uma ordem de grandeza incompatível com a realidade medida (para mais informação consultar Castro (2011)). Apresentam-se as estatísticas descritivas dos dados na Tabela 3, que evidenciam a heterogeneidade da amostra analisada.

Tabela 3 - Estatística Descritiva das Variáveis Utilizadas no Modelo de DEA

\begin{tabular}{lllll}
\hline \multicolumn{1}{c}{ Variável } & Média & $\begin{array}{l}\text { Desvio } \\
\text { Padrão }\end{array}$ & Máximo & Mínimo \\
\hline Inputs & 1350 & 1262 & 6420 & 46 \\
\hline$x_{1}-\mathrm{N}^{\circ}$ Horas Médicos (h) & 1509070 & 1371092 & 6099323 & 27602 \\
\hline$x_{2}-$ Custos Enfermeiros (€) & 1476455 & 1532799 & 7980923 & 27687 \\
\hline$x_{3}-$ Custos Exames Ponderados (€) & 1410007 & 1625900 & 8805764 & 297 \\
\hline$x_{4}-$ Custos Matérias Ponderadas (€) & 78 & 58 & 260 & 0 \\
\hline$x_{5}-\mathrm{N}^{\circ}$ Camas & & & & \\
\hline Outputs & 28159 & 21068 & 102931 & 0 \\
\hline$y_{1}-$ Tempo Estadia Total (dias) & 2680 & 2568 & 15032 & 0 \\
\hline$y_{2}-\mathrm{N}^{\circ}$ Altas Internamento (com correção & & & & 5329 \\
\hline pelo case-mix) & 8350 & 6334 & 23932 & 108 \\
\hline$y_{3}-\mathrm{N}^{\circ}$ de Consultas Externas & 1665 & 1436 & 8324 & \\
\hline$y_{4}-\mathrm{N}^{\circ}$ Primeiras Consultas & & & & \\
\hline
\end{tabular}

Utilizou-se o software não-comercial EMS (Efficiency Measurement System) para calcular os resultados de eficiência das diferentes unidades. Começou-se

3 Em vez de um único valor de case-mix, a ACSS discrimina a diferente complexidade de um internamento ou ocorrência em ambulatório devido a doenças do foro cirúrgico e de foro médico. 
por calcular o valor da eficiência considerando que se estaria perante uma situação de rendimentos constantes à escala. No entanto, verificou-se que as unidades consideradas eficientes eram todas de pequena dimensão, existindo uma tendência de decréscimo da eficiência com o aumento da dimensão dos serviços, representada pelo número de camas. Assim sendo, adotou-se um modelo de DEA de rendimentos variáveis à escala. Ao calcular os valores de eficiência para este novo modelo, concluiu-se que o número de unidades consideradas eficientes era muito elevado (28 dos 48 serviços de medicina interna), fruto da existência de vários pesos nulos, que eliminaram a influência da respetiva variável. Assim, decidiu-se introduzir restrições aos valores dos pesos, usando o método da região de confiança, de forma a impedir que as unidades pudessem optar por valorizações irreais dos diferentes fatores.

Para se identificar as restrições a aplicar aos pesos das diferentes variáveis, começou por identificar-se a importância relativa de cada output e input. Começando pelos outputs, analisaram-se os custos unitários das duas linhas de produção consideradas. Os resultados apresentam-se na Tabela 4.

Tabela 4 - Custos Unitários por Unidade Produzida nos Serviços de Medicina Interna

\begin{tabular}{lll}
\hline Variável de Output & \multicolumn{1}{c}{ Volume } & Custo Unitário Médio \\
\hline$y_{2}$ & 157.207 altas & $2.091,39 € /$ alta \\
\hline$y_{1}$ & 1.366 .808 dias internamento & $240,55 € /$ dia internamento \\
\hline$y_{3}$ & 517.972 consultas & $155,28 € /$ consulta \\
\hline
\end{tabular}

Estes resultados revelam que, na dimensão referente à quantidade total de tratamento produzido, o peso da variável referente ao internamento deverá ser igual a pelo menos 1,5 vezes o peso da variável referente às consultas externas (valor obtido do rácio entre os custos unitários das consultas e dos dias em internamento). Para impedir uma excessiva disparidade na razão entre os pesos destas variáveis, restringiu-se o limite superior desta relação ao valor de 5 . A consideração deste limite está relacionada com a manutenção da ordem de 
grandeza entre os pesos ${ }^{4}$. Isto permite que os pesos tomem valores de magnitude semelhante, sem, no entanto, se restringir excessivamente a capacidade de cada DMU escolher os seus pesos, o que resulta nas primeiras restrições:

$$
1,5 \leq \frac{u_{1}}{u_{3}}<5
$$

De forma a não tornar o modelo demasiado restritivo, apenas se restringiu esta razão entre outputs de linhas de produção distintas (consultas e internamento).

Relativamente à dimensão referente ao acesso aos cuidados, apenas foi possível obter informação para a linha de produção de internamento (ver Tabela 4 , onde falta $\left.y_{4}\right)$. Nesta linha, verifica-se que esta dimensão $\left(y_{2}\right)$ apresenta um custo unitário aproximadamente dez vezes superior à dimensão da quantidade de tratamento $\left(y_{1}\right)$. Assim, optou-se por impor limites à relação entre os pesos que refletissem essa magnitude, embora permitindo também alguma flexibilidade em torno do valor 10 (entre 5 e 50$)^{5}$ :

$$
5 \leq \frac{u_{2}}{u_{1}}<50
$$

Novamente, esta limitação apenas elimina as possibilidades de produção irreais, deixando ao modelo de DEA a capacidade de dar às unidades uma liberdade de escolha dos pesos plausível. Este é um intervalo muito lato, que reflete apenas uma limitação à magnitude das razões que se pretende obter, para que as unidades não deixem de pesar todos os outputs.

\footnotetext{
${ }^{4} \mathrm{O}$ conceito de ordem de grandeza de um número identifica, na escala decimal, a quantidade de números 10 que um número contém. Convenciona-se internacionalmente que um número x é da ordem de grandeza $n$ se:

$$
5 \times 10^{n-1} \leq x<5 \times 10^{n}
$$

Neste caso, 5 será o valor limite para a relação entre os pesos permanecer na mesma ordem de grandeza: 0 , que vem de $10^{\circ}$.

${ }^{5}$ Da mesma forma que antes, para que agora se reflita uma relação de ordem de grandeza 1: $10^{1}$.
} 
Dada a inexistência de informação quanto à dimensão de acesso na linha de produção de consulta externa $\left(y_{4}\right)$, considerou-se que a relação entre as suas duas dimensões seria semelhante à existente na linha de internamento. Por conseguinte, aplicaram-se nesta linha de produção restrições semelhantes às da linha de produção relativa ao internamento:

$$
5 \leq \frac{u_{4}}{u_{3}}<50
$$

Para identificar a importância de cada input, analisou-se a distribuição dos custos que cada uma das variáveis representa em todos os serviços de Medicina Interna. Os resultados apresentam-se na Figura 4, que evidencia que cada uma das cinco variáveis de input aqui consideradas tem uma importância muito semelhante nos custos totais do serviço em análise.

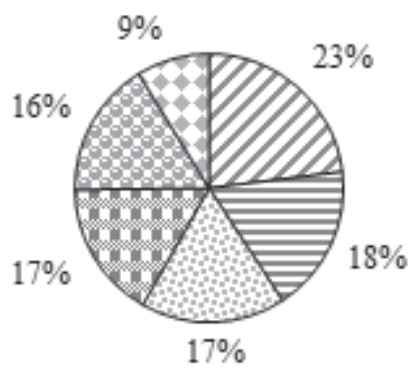

$\square$ Camas

日Enfermeiros

$\triangle \mathrm{MCDT}$

DCMVMC

๑édicos

口Outros

Figura 4 - Distribuição dos Custos Gerais nos Serviços de Medicina Interna Representados pelas Variáveis de Interesse.

Para que se reflita nos resultados a importância relativa semelhante de cada input, sem se restringir demasiado a liberdade de escolha de cada DMU (como se fez no lado dos outputs), optou-se por forçar os hospitais a pesarem todos os inputs, já que nenhum parece ter uma importância superior aos restantes e não seria "admissível" que um hospital se tornasse eficiente por pesar apenas alguns inputs, negligenciando os restantes. Nesse sentido, limitaram-se as relações entre todos os inputs e o input "número de horas médicos" $\left(x_{1}\right)$, permitindo mesmo assim margens de variação latas entre os pesos virtuais de cada input e de $x_{1}$. De notar que neste caso as restrições impostas são entre os 
pesos virtuais de um hospital fictício, usando inputs médios. A opção por restrições aos pesos virtuais deveu-se às diferentes unidades de medida das variáveis. Como se pode ver em (17) estas restrições virtuais convertem-se em Assurance Regions.

$$
\begin{aligned}
& 0,5 \leq \frac{v_{i} \overline{x_{l}}}{v_{1} \overline{x_{1}}}<5 \Leftrightarrow \\
& 0,5 \times \frac{\overline{x_{1}}}{\overline{x_{l}}} \leq \frac{v_{i}}{v_{1}}<5 \times \frac{\overline{x_{1}}}{\overline{x_{l}}}
\end{aligned}
$$

Dado que se pretendia apenas limitar a magnitude das razões entre os pesos de forma lata, arredondou-se o rácio dos valores médios dos inputs para a potência de base 10 mais próxima ${ }^{6}$. Assim, resultaram as seguintes restrições, aplicadas aos pesos dos inputs:

$$
\begin{aligned}
& 0,5 \times 10^{-3} \leq \frac{v_{2}}{v_{1}}<5 \times 10^{-3} \\
& 0,5 \times 10^{-3} \leq \frac{v_{3}}{v_{1}}<5 \times 10^{-3} \\
& 0,5 \times 10^{-3} \leq \frac{v_{4}}{v_{1}}<5 \times 10^{-3} \\
& 0,5 \times 10^{1} \leq \frac{v_{5}}{v_{1}}<5 \times 10^{1}
\end{aligned}
$$

\subsection{Discussão dos Resultados da Avaliação de Eficiência}

Na Figura 5 apresenta-se a distribuição das eficiências obtidas para os 49 hospitais analisados. A média dos resultados obtidos foi de 74,2\%, com um desvio padrão de 20,1\%. O valor mínimo de eficiência obtido foi de 38,4\%. Dos resultados, destaca-se a grande amplitude dos valores de eficiência, o que evidencia uma grande disparidade de desempenhos. Aproximadamente um quinto dos hospitais foi considerado eficiente (10 em 48) e é semelhante o número de hospitais com um nível de eficiência baixo (7, abaixo dos 50\%) e alto (9, entre os $80 \%$ e 100\%). A grande maioria dos hospitais, 22, encontra-se no entanto num nível médio de eficiência (entre 50\% e 80\%). Esta análise permite concluir que há uma grande margem de melhoria da eficiência dos serviços de Medicina Interna, o que justifica a relevância deste assunto para a gestão hospitalar (para mais detalhes de resultados consultar Castro (2011)).

\footnotetext{
${ }^{6}$ Novamente, entra aqui o conceito de ordem de grandeza de um número.
} 


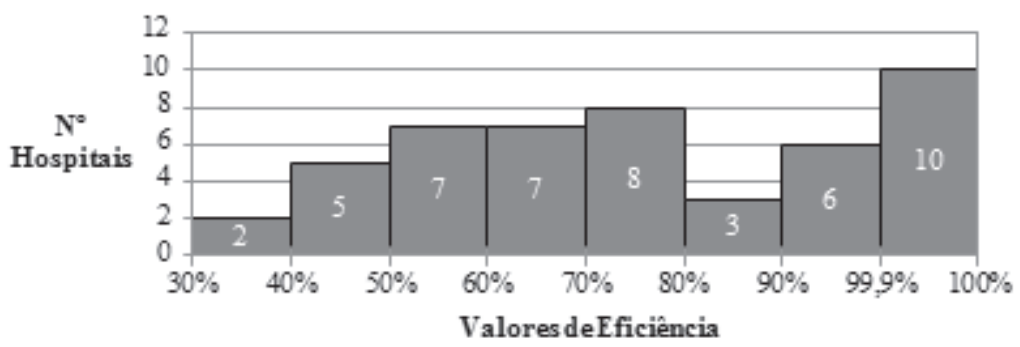

Figura 5 - Distribuição dos Valores de Eficiência.

Calculando a razão entre a média dos valores das variáveis de input e de output das unidades mais ineficientes (eficiência inferior a 80\%) e as eficientes, como se apresenta na Figura 6, normalizando para os valores destas últimas, percebemos que os serviços de medicina interna mais ineficientes apresentam tempos de internamento e número de consultas externas semelhantes aos serviços eficientes, apresentando menos altas de internamento e menor número de primeiras consultas. Ainda assim, estas unidades apresentam custos bastante superiores aos das unidades eficientes, particularmente em matérias ponderadas, cujos custos são cerca de 1,5 vezes superiores. Os custos com exames ponderados e com enfermeiros também são superiores, mas não se verificam muitas diferenças no $\mathrm{n}^{\circ}$ de camas e nas horas de médicos entre os serviços eficientes e ineficientes.

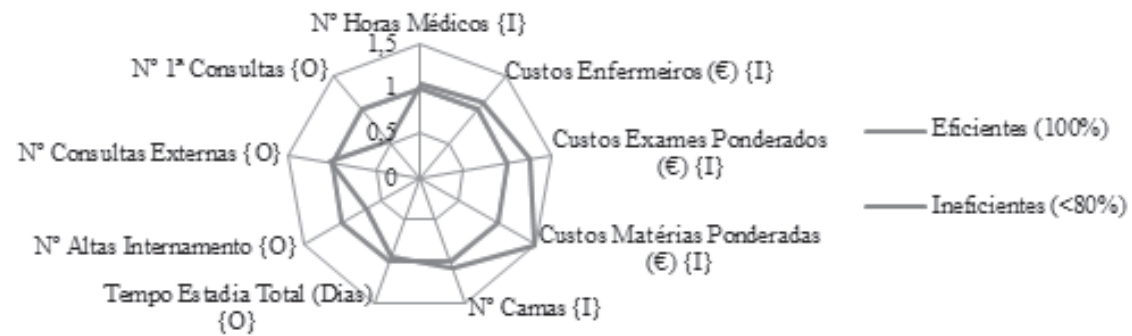

Figura 6 - Comparação entre Valores Médios de Unidades Eficientes e Ineficientes.

Nos hospitais avaliados, o total das poupanças potenciais obtidas através da eliminação das ineficiências é apresentado na Figura 7. Pode concluir-se que, 
tal como verificado anteriormente, as matérias ponderadas, os enfermeiros e os MCDT são as áreas onde será possível obter maiores poupanças

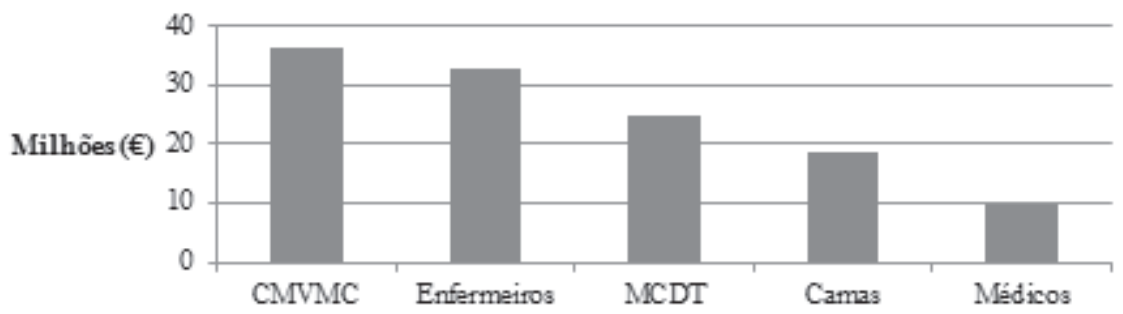

Figura 7 - Potencial de Poupanças a Obter Identificadas pelo Modelo.

A análise com DEA permite identificar as oportunidades de melhoria de hospitais, individualmente. Apresenta-se na Figura 8, a título de exemplo, a razão entre os valores das variáveis para um hospital com resultado de eficiência de $73,1 \%$ e a média dos valores para os seus benchmarks (três hospitais). Neste exemplo, é possível verificar como este hospital se compara com uma unidade ideal (uma ponderação dos seus três benchmarks) que tem praticamente o seu nível de outputs. Assim, é possível identificar quais os excessos de inputs que este hospital apresenta e que o afastam da fronteira das melhores práticas. No caso dos CMVMC, a categoria em que este hospital deve apostar mais para melhorar o seu desempenho neste serviço, verifica-se que a razão entre o valor do input observado e o ideal é cerca de 4,5.

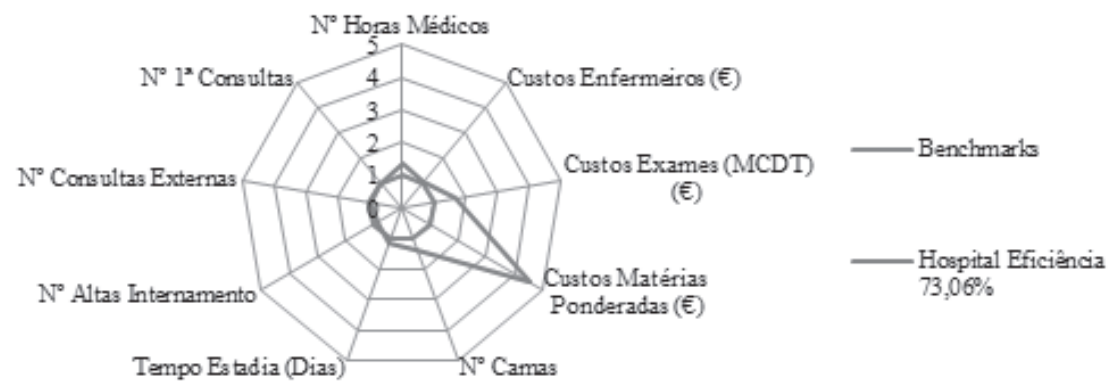

Figura 8- Comparação entre Valores Médios de uma Unidade e seus Benchmarks. 


\section{Conclusões e Trabalho Futuro}

O trabalho aqui desenvolvido foi realizado no âmbito do projeto "Benchmarking de Hospitais Portugueses", que tem como objetivo desenvolver uma plataforma web de benchmarking para os hospitais portugueses. Pretendese que esta possa ser utilizada numa efetiva avaliação dos hospitais, permitindo observar-se e melhorar continuamente o seu desempenho, assim como permitir ao público em geral escrutinar e até escolher os prestadores dos serviços de saúde. A plataforma ambiciona apresentar uma panóplia alargada de indicadores que incidam sobre as várias atividades hospitalares e recorrer a técnicas de fronteira, para agregar alguma dessa informação em indicadores globais que permitam uma mais fácil comparação de hospitais.

Neste trabalho idealizou-se um modelo para avaliar os diferentes serviços principais, na ótica da eficiência hospitalar. Este modelo teve por base uma revisão bibliográfica que permitiu identificar as variáveis mais comuns e passíveis de ser usadas num modelo de DEA, e um estudo exaustivo da contabilidade analítica dos hospitais do SNS, que permitiu identificar as variáveis responsáveis pela maior proporção de custos. Como exemplificado na implementação prática, quando aplicado a cada um dos serviços de um hospital, o modelo tem de ser adaptado mas não deixa de ter uma identidade genérica.

A aplicação do modelo de DEA ao serviço de Medicina Interna, permitiu comparar os níveis de eficiência deste serviço em hospitais distintos. O modelo permitiu identificar, para os serviços ineficientes, serviços eficientes com características semelhantes, que podem ser usados para compreender melhor as melhorias que cada unidade pode fazer, no sentido de caminhar para um melhor desempenho. No caso da Medicina Interna, verificou-se que os maiores ganhos de eficiência podem ser realizados através de reduções nos custos dos medicamentos e material clínico.

Há ainda muito trabalho pela frente para se operacionalizar uma avaliação aos hospitais. Em primeiro lugar, faltará validar o modelo proposto junto dos principais utilizadores, os gestores hospitalares. Faltará também averiguar as razões para a falta de coerência apresentada pelas diferentes fontes de informação fornecidas pelo mesmo organismo do Estado e tentar identificar 
uma forma de se solucionar este problema. Posteriormente será necessário idealizar uma forma de agregar os resultados de eficiência de cada serviço numa medida única a atribuir a cada hospital, de forma a permitir uma comparação global entre os hospitais (e percecionar o desempenho dos gestores hospitalares). Tendo os serviços transversais e auxiliares um peso significativo nos custos diretos dos hospitais, será também importante fazer-se a sua avaliação.

Será fundamental aferir-se a eficácia no tratamento dos pacientes, através de modelos de avaliação do tratamento das doenças. Sem isto, o modelo aqui apresentado perde algum do fundamento de existir. Para isto será fundamental o envolvimento de clínicos, dada a sua capacidade única de aferir a capacidade das variáveis do modelo representarem adequadamente o que se pretende medir. Por outro lado, a sua colaboração é essencial para validar e apoiar a aceitação por parte da classe médica dos modelos a propor. Será também interessante verificar se existe ou não antagonismo nos valores dos indicadores agregadores das medidas de eficiência e de eficácia dos hospitais.

Apesar de todos os constrangimentos, os desenvolvimentos alcançados com este trabalho foram significativos, nomeadamente com a concretização de um modelo de avaliação ao nível dos serviços hospitalares, unidades verdadeiramente comparáveis mas até aqui não abordadas na literatura nacional. A aplicação de DEA permite comparar os hospitais recorrendo a uma medida única, mas tendo por base um conjunto alargado de indicadores, cuja importância individual é definida no interesse de cada avaliado. Espera-se, por isso, que este trabalho contribua para uma mais efetiva avaliação dos hospitais e se consiga, assim, promover a melhoria da sua eficiência, sem prejuízo da sua eficácia.

\section{Agradecimentos}

Agradecemos à Fundação para a Ciência e a Tecnologia (FCT) que, através da bolsa de doutoramento SFRH/BD/76634/2011 e do projeto HOBE Benchmarking Hospitais Portugueses (PTDC/EGE-GES/112232/2009), financiou este trabalho. 


\section{REFERÊNCIAS}

Banco Central Europeu, Comissão Europeia, Fundo Monetário Internacional, República Portuguesa e Ministério das Finanças e da Administração Pública. 2011. Portugal: Memorando de Entendimento sobre as Condicionalidades de Política Económica (tradução de 17 de Maio de 2011). Disponível em: infoeuropa.eurocid.pt/registo/000046743/

Banker, R.D., A. Charnes e W.W. Cooper. 1984. Some Models for Estimating Technical and Scale Inefficiencies in Data Envelopment Analysis. Management Science 30(9): 1078-1092.

Barros, P.P. e J.d.A. Simões. 2007. Portugal: Health System Review. Health Systems in Transition. Vol. 9(5): 1-140.

Camp, R.C. 1989. The Search for Industry Best Practices that Lead to Superior Performance. Milwaukee, Wisconsin: ASQC Quality Press.

Castro, R.A.S. 2011. Benchmarking de Hospitais Portugueses - Modelação com Data Envelopment Analysis Dissertação de Mestrado, Faculdade de Engenharia, Universidade do Porto, Porto.

Charnes, A., W.W. Cooper e E. Rhodes. 1978. Measuring Efficiency of Decision-Making Units. European Journal of Operational Research 2(6): 429-444.

Chilingerian, J.A. e H.D. Sherman. 2004. Health Care Applications: From Hospitals to Physicians, From Productive Efficiency to Quality Frontiers. em Handbook on Data Envelopment Analysis, editado por Cooper, W. W., L. M. Seiford e J. Zhu. Boston / Dordrecht / London: Kluwer Academic Publisher.

Cooper, W.W., L.M. Seiford e K. Tone. 2007. Data Envelopment Analysis: A Comprehensive Text with Models, Applications, References and DEA-Solver Software. ( $2^{\mathrm{a}}$ ed.). Nova Iorque: Springer Science and Business Media, LLC.

Costa, C. e S. Lopes. 2007. Avaliação do Desempenho dos dos Hospitais Públicos em Portugal Continental - 2005. Escola Nacional de Saúde Pública - Universidade Nova de Lisboa.

Dismuke, C. e V. Sena. 2001. Is there a Trade-Off between Quality and Productivity? The Case of Diagnostic Technologies in Portugal. Annals of Operations Research 107(1): 101-116.

Donabedian, A. 1980. The definition of quality and approaches to its assessment. Vol. 1. Ann Arbor, Michigan: Health Administration Press.

Fried, H.O., C.A.K. Lovell e S.S. Schmidt. 2008. Efficiency and Productivity. em The Measurement of Productive Efficiency and Productivity Growth, editado por Fried, H. O., C. A. K. Lovell e S. S. Schmidt. New York: Oxford University Press.

Gonçalves, L.F.M. 2008. Análise da eficiência dos hospitais SA e SPA segundo uma abordagem de fronteira de eficiência. Tese de Doutoramento, ISCTE, Lisboa.

Hollingsworth, B. 2008. The measurement of efficiency and productivity of health care delivery. Health Economics 17(10): 1107-1128.

Hollingsworth, B., P.J. Dawson e N. Maniadakis. 1999. Efficiency measurement of health care: a review of non-parametric methods and applications. Health Care Manag Sci 2(3): 161-172.

Kontodimopoulos, N. e D. Niakas. 2005. Efficiency measurement of hemodialysis units in Greece with data envelopment analysis. Health Policy 71(2): 195-204.

Koopmans, T.C. 1951. Actvity Analysis of Production and Allocation. Editado por Sons, J. W. a. New York. 
Marshall, M., S. Leatherman e S. Mattke. 2004. Selecting Indicators for the Quality of Health Promotion, Prevention and Primary Care at the Health Systems Level in OECD Countries. OECD Health Technical Papers. OECD Publishing. No. 16.

Moreira, S. 2008. Análise da Eficiência dos Hospitais-Empresa: Uma Aplicação da "Data Envelopment Analysis". Boletim Económico, editado por Banco de Portugal. Vol. Primavera.

Nayar, P. e Y.A. Ozcan. 2008. Data Envelopment Analysis comparison of hospital efficiency and quality. Journal of Medical Systems 32(3): 193-199.

O'Neill, L., M. Rauner, K. Heidenberger e M. Kraus. 2008. A cross-national comparison and taxonomy of DEA-based hospital efficiency studies. Socio-Economic Planning Sciences 42(3): 158189.

Oliveira, M., S.N.d. Silva, J. Pereira, J. Simões, P.P. Barros, A.S. Ferreira, P.S. Ferreira, A.P. Hespanhol e M. Teixeira. 2007. A Sustentabilidade Financeira do Serviço Nacional de Saúde. editado por Miistério da Saúde - Secretaria Geral

Pordata. 2011. Pordata - Base de Dados Portugal Contemporâneo. Fundação Francisco Manuel dos Santos [último acesso a 25 de Fevereiro de 2011]. Disponível em: www.pordata.pt.

Puig-Junoy, J. 1998. Technical efficiency in the clinical management of critically ill patients. Health Economics 7(3): 263-277.

Simões, J. 2004. Retrato Político da Saúde - Dependência do Percurso e Inovação em Saúde: da Ideologia ao Desempenho. Livraria Almedina.

Thanassoulis, E., M.C. Portela e R. Allen. 2004. Incorporating Value Judgements in DEA. em Handbook on Data Envelopment Analysis, editado por Cooper, W. W., L. M. Seiford e J. Zhu: Kluwer Academic Publishers.

Thompson, R.G., F.D. Singleton, R.M. Thrall e B.A. Smith. 1986. Comparative site evaluations for locating a high-energy Physics lab in Texas. Interfaces 16(6): 35-49.

Triantafillou, P. 2007. Benchmarking in the public sector: A critical conceptual framework. Public Administration 85(3): 829-846.

Tribunal de Contas. 2006. Relatório Global de Avaliação do Modelo de Gestão dos Hospitais do SEE - Período de 2001-2004. Relatório n. ${ }^{\circ}$ 20/06 - Audit. Vol. I-II.

Voss, C.A., P. Åhlström e K. Blackmon. 1997. Benchmarking and operational performance: some empirical results. Benchmarking for Quality Management \& Technology 4(4): 273-285. 